\title{
Assessment of the Levels of Brominated Flame Retardants in Computers and Televisions in Selected Regions of Eritrea
}

\author{
Afewerki Tesfagabr'1, Tesfamichael Haile1, Mussie Sium11, Teame Tekleab² \\ ${ }^{1}$ Department of Chemistry, College of Science, Eritrea Institute of Technology, Mai Nefhi, Eritrea \\ ${ }^{2}$ Department of Environment, Ministry of Land, Water and Environment, Asmara, Eritrea \\ Email: afewerkit@yahoo.com, mussies2013@gmail.com
}

How to cite this paper: Afewerki, T., Tesfamichael, H., Mussie, S. and Teame, T. (2018) Assessment of the Levels of Brominated Flame Retardants in Computers and Televisions in Selected Regions of Eritrea. Open Access Library Journal, 5: e5061.

https://doi.org/10.4236/oalib.1105061

Received: November 20, 2018

Accepted: December 16, 2018

Published: December 19, 2018

Copyright (c) 2018 by authors and Open Access Library Inc.

This work is licensed under the Creative Commons Attribution International License (CC BY 4.0).

http://creativecommons.org/licenses/by/4.0/

\begin{abstract}
During recent years, electronic waste (e-waste) around the world is growing at a fast rate and has become a matter of concern due to the presence of toxic brominated flame retardants (BFRs) and certain heavy metals. Currently, in Eritrea there is low awareness on the harmful effects of e-wastes, lack of proper storage facilities and no proper policy and legislative framework related to e-wastes. Thus, in most cases e-wastes still reside in homes, offices, and some are stored with other materials in different places. Therefore, the objective of the present study was to assess the levels of BFRs in obsolete as well as in lately imported computers and televisions using hand held hazardous substances analyzer-Genius 3000 XRF. The survey was done in selected regions of Eritrea and thus a total of 223 samples of computers and TVs from 78 different products were screened. Three readings at forty seconds were conducted for each sample and the average value was calculated. From 173 sampled computers, both oldest and lately imported products, different levels of $\mathrm{Br}$ were measured varying from the lowest detectable amount $(0.3689$ $\mathrm{ppm})$ to the highest $(87,821 \mathrm{ppm})$. Similarly, out of 50 screened old and new models of TVs various levels of $\mathrm{Br}$ were determined with minimum detectable level $(1.5793 \mathrm{ppm})$ and highest level $(80,916 \mathrm{ppm})$. The analysis displayed high levels of $\mathrm{Br}$ both in the obsolete and lately manufactured products. The concentration of Br didn't show any consistency either to the product type or manufacturing time. This is a very first preliminary study conducted related to the levels of BFRs in electronic wastes in the country and thus in order to evaluate the environmental impacts and health hazards caused by BFRs and other toxic materials of e-wastes, further study using advanced analytical methods is mandatory.
\end{abstract}




\section{Subject Areas}

Composite Material

\section{Keywords}

Electronic Waste, Polybrominated Flame Retardants, Genius 3000 XRF, Eritrea

\section{Introduction}

During recent years, one special type of waste has raised a great concern in most of the developed and in developing countries is the electronic waste (e-waste). Currently, waste of electrical and electronic equipment (WEEE) or e-waste is one of the fastest growing waste streams in the world but it has not yet got the compulsory attention [1] [2]. Rapid economic growth and changes in technology coupled with urbanization, falling prices, and planned obsolescence have resulted in a fast growing surplus of e-waste around the globe, and have raised great concerns as many components in these products are hazardous heavy metals, toxic chemicals and non-biodegradable plastics [3] [4].

The amount of e-waste generated globally is growing at a rate nearly three times faster than the growth of overall municipal solid waste. The amount of e-waste generated in 2016 was 44.6 million tons, and expected to project in an annual growth rate of $4 \%-5 \%$. From the most recent comprehensive study in 2014, the United Nations University (UNU) estimated global WEEE generation to be 41.8 million metric tons, and forecasted an increase to 50 million metric tons by 2018 [5] [6]. Although it is illegal under the Basel Convention of 1992, it is estimated that $75 \%$ to $80 \%$ of that produced in developed countries is shipped to developing countries where the environmental standards are low or nonexistent and working conditions are poor; especially in Asian and African countries for cheaper recycling and disposal [1] [7] [8]. Another large fraction of the e-waste generated in the world is treated as general municipal solid waste, and is thus incinerated in waste incineration facilities or just dumped on landfills [9] (SEPA, 2011). It contains both valuable and hazardous materials that require special handling and recycling methods to avoid adverse environmental and human health impacts [10] [11].

E-waste is highly complex to handle since it is made up of multiple components and usually contains precious metals; especially copper, silver, gold and platinum [12] [13], and various plastics. However, the greatest concern about e-waste is that the presence of potential environmental contaminants, especially persistent organic compounds, such as brominated flame retardants (BFRs), phthalates, and polychlorinated biphenyls (PCBs) [14]. Moreover, the presence of lead, antimony, mercury, cadmium, nickel, barium, arsenic, and beryllium has serious consequences [1] [8] [9]. Burning e-waste may generate polybrominated 
dioxins and furans [4] which are classified as "known carcinogens" by world health organization [1], polycyclic aromatic hydrocarbons (PAHs) and polyhalogenated aromatic hydrocarbons (PHAHs) [10]. Such harmful substances can be deposited into the surrounding soil, water and air during waste treatment or when they are dumped in landfills or kept in stores [15] [16].

Despite of their benefits for reducing fire-related injury and property damage, growing concern for BFRs has risen because of their occurrence and persistence in the environment, biota and humans [17]. Evidence of their persistence and capacity for bioaccumulation, coupled with concerns about their adverse health effects has led to widespread bans and restrictions on the manufacture and use [18]. The use of toxic BFRs especially polybrominated diphenyl ethers (PBDEs) as flame retardants (FRs) have been phased out or banned. However, exposure is expected to continue for several decades because of the reservoir of these chemicals that exist in consumer products that have long durations of use, and the environmental stability of PBDEs [19]. Humans particularly workers and local residents exposed to the WEEE are therefore highly liable to a wide range of toxic compounds via dust originating from these activities [20]. Most of what is known about the toxicity of BFRs arises from animal studies and in vitro assays, especially as ethical concerns prevent controlled studies on human subjects [21]. Therefore, PBDEs have been extensively investigated as possible TH disruptors in animal studies. Many in vivo toxicological studies in animal models have reported a reduction in total thyroxine (TT4) [22], neurological and developmental disorders, reproductive health effects, and cause endocrine disruption and thyroid gland dysfunction [21] [23].

In Eritrea, all the electrical and electronic equipments (EEEs) are imported from foreign countries, except the computers known as e-tech and NCC are assembled in the country. Since the government has been enhancing information and communication technologies (ICTs); EEEs especially computers became the most common and widely used gadget in all kinds of activities ranging from offices, elementary to higher schools, residences, manufacturing industries...etc. Additionally, as people are eager for newer technologies, the consumption of electronics is dramatically increasing, while the lifespan of electronics is becoming relatively short. Consequently, older and outdated products are becoming obsolete and being stored as e-waste in large quantities and at increasing rates. Therefore, the lack of clear framework for handling and treatment of e-waste has led to accumulated electronic and electrical waste in offices and warehouses throughout the country. In most cases, e-wastes still reside in homes, offices, stores and mixed with other items. This is because of low awareness of citizens on the harmful effects of WEEE on the environment and their health, lack of storage facilities and inadequate infrastructure for WEEE management, proper policy and legislative framework. As a solution to the storage problem, e-wastes from different governmental institutions are collected and stored at different places without adequate management. In this study, the preliminary assessment 
of BFRs found in computers and Televisions was conducted from diverse Zones in Eritrea including Central, Anseba and Northern Res-Sea. The concentration of bromine was determined to estimate indirectly the levels polybrominated flame retardants which are potential health hazard chemicals. Therefore, the results from this report will help to elaborate the current status and future trend of e-wastes in the country.

\section{Materials and Methods}

\subsection{Instrumentation}

The instrument used in this study, to determine the level of $\mathrm{Br}$, in computers and TVs was the handheld hazardous substances analyzer Genius $3000 \mathrm{X}$-Ray Fluorescence (XRF) spectrometer (Skyray Company). It is small, easy to carry, and supports handheld field online analysis during raw materials inspection, process control and finished product inspection. It can measure the level of $\mathrm{Br}$ directly by placing the measurement window close to the sample to be analyzed.

\subsection{Sampling and Data Collection}

Different Governmental Institutions were selected due to the availability of stores of obsolete computers and large number of computers still in use. Therefore, the data for old and new computers was collected from diverse sites including University of Asmara, Asmara Technical School, Governmental Property Disposal Store, Eritrea Institute of Technology (EIT), Asha-Golgol, College of Marine Science and Technology, Authority of Port of Massawa, Ministry of Marine Resource Massawa, and Hamelmalo College of Agriculture. Moreover, in this study older and newly imported TVs were selected from various repairing shops and vocational training centers in Asmara. During the sample analysis different types of TVs, which have long range of life were selected. A typical electronic product is made up of hundreds of individual components. Complete testing of each product was usually impractical due to time and sample preparation constraints. This challenge was mainly addressed by focusing on the samples of known "high concern" materials like CRT casings (TVs and computer monitors) and printed circuit boards.

\section{Results and Discussion}

As the primary objective of this study was to measure the concentration of bromine and thus estimate the levels of BFRs in the electronic products, 223 samples of both computers and televisions of 78 diverse products were screened. The WEEE and/or EEE samples were manufactured from the late 1980s up to 2015; however the manufacturing time was not available in some products. Most of these products were imported from Asian countries including China, India, Japan, and Korea, and some were from Europe and USA and few were assembled in Eritrea. Different concentration of $\mathrm{Br}$ was detected in almost all the samples and there was high degree of variability within the products. Unexpectedly, high 
level of $\mathrm{Br}$ was also determined in the recently imported products. There has not been comprehensive data on the status of computers or other electronic equipments in Eritrea. Therefore, the e-waste generated can be estimated from the life span of those products and increasing use of EEEs. As observed during the field surveys and data collection, currently the main e-waste contributors are governmental sectors. Though there are not much e-wastes generated from individual households, they will become potential contributors in the future because the trend of consumption of electrical equipments in increasing.

\subsection{Computers}

From the 173 sampled computers of a wide range of manufacturers, a total of around 4 kilogram of $\mathrm{Br}$ was determined in both the old and lately imported products. The level and range of the concentration of Br analysed in the samples of computers found in different governmental sectors are also displayed in Table 1 and Figure 1 respectively. The level of $\mathrm{Br}$ was varying from the lowest detectable amount $(0.3689 \mathrm{ppm})$ up to the highest $(87,821 \mathrm{ppm})$. Generally, from the examined computers, 24 (15\%) were in the range of $1000-10,000,49(29 \%)$ had $\mathrm{Br}$ concentration between 10,000 and $20,000 \mathrm{ppm}, 29$ (17\%) in the range of 20,000 to $30,000 \mathrm{ppm}, 21$ (12\%) were between 30,000 to $50,000 \mathrm{ppm}$ and 24 (14\%) computers had greater than 50,000 ppm. The overall tally of computers with high level (above the defined limit) of Br was about 147 (85\%); this clearly indicates that the examined samples had high levels of brominated flame retardants. However, the level of $\mathrm{Br}$ was not detectable only in 7 (4\%) computers, and the level of $\mathrm{Br}$ in 19 (11\%) samples was below the limit $(<1000 \mathrm{ppm})$. Various concentrations of $\mathrm{Br}$ were detected in the different samples and there was no uniform pattern in the levels of $\mathrm{Br}$ relative to the type and age of the electronic products. Relatively, large percentage of the computers had $\mathrm{Br}$ concentration in the range of 10,000-20,000 ppm and as shown in Figure 1, there was no uniform pattern in the increment of the range of Br concentration.

Most importantly, screening of the obsolete computers found in the Ministry of Marine Resource displayed relatively low $\mathrm{Br}$ concentration, with maximum value of $16,921 \mathrm{ppm}$, as compared to the other results. This could be due to the hot weather in Massawa; there is high possibility of volatilizing the brominated organic materials because the old computers are found in an open area. Therefore, these toxic substances can critically affect the health of community living in the vicinity of the open store by entering their body through respiratory tracts and marine foods. According to U.S Environmental Protection Agency (2006) [24], direct exposure to commercial PBDE mixtures is assumed to be the main source of PBDE uptake/accumulation in biota; it is plausible that PBDE mixtures may contribute to the loading of persistent PBDEs in marine food webs.

Samples of the screened obsolete computers of different brands and models manufactured at different times are displayed in Table 2. However, the concentration of bromine didn't show any consistency with the manufacturing time or type of the product. For example, the levels of $\mathrm{Br}$ (in ppm) in the screened IBM 
Table 1. Variation of bromine concentrations (in ppm) obtained from various samples of computers.

\begin{tabular}{cccccccccccc}
\hline Range (ppm) & UoA & ATS & GPDS & AG & EIT & MC & PoM & MMR & ZA & Total & $\%$ \\
\hline$<$ detection limit & 1 & 1 & 0 & 1 & 0 & 2 & 0 & 1 & 1 & 7 & 4 \\
$>0 \leq 1000$ & 3 & 4 & 2 & 1 & 1 & 1 & 2 & 5 & 0 & 19 & 11 \\
$>1000 \leq 10,000$ & 2 & 3 & 2 & 2 & 2 & 7 & 2 & 2 & 2 & 24 & 15 \\
$>10,000 \leq 20,000$ & 7 & 2 & 6 & 14 & 3 & 6 & 4 & 2 & 4 & 49 & 29 \\
$>20,000 \leq 30,000$ & 11 & 3 & 7 & 4 & 0 & 0 & 1 & 0 & 3 & 29 & 17 \\
$>30,000 \leq 40,000$ & 2 & 2 & 3 & 0 & 0 & 2 & 2 & 0 & 0 & 11 & 6 \\
$>40,000 \leq 50,000$ & 3 & 1 & 4 & 0 & 0 & 1 & 0 & 0 & 1 & 10 & 6 \\
$>50,000 \leq 60,000$ & 2 & 0 & 2 & 1 & 0 & 0 & 3 & 0 & 1 & 9 & 5 \\
$>60,000 \leq 70,000$ & 4 & 3 & 0 & 0 & 0 & 1 & 0 & 0 & 1 & 9 & 5 \\
$>70,000$ & 1 & 0 & 1 & 0 & 0 & 2 & 0 & 0 & 2 & 6 & 3 \\
Total & 36 & 20 & 27 & 23 & 6 & 22 & 14 & 10 & 15 & 173 & 100 \\
\hline
\end{tabular}

NB: UoA (University of Asmara); ATS (Asmara Technical School); GPDS (Governmental Property Disposal Store); AG (ASha-Golgol); EIT (Eritrea Institute of Technology); MC (Marine College); PoM (Port of Massawa); MMR (Ministry of Marine Resource); ZA (Zoba Anseba).

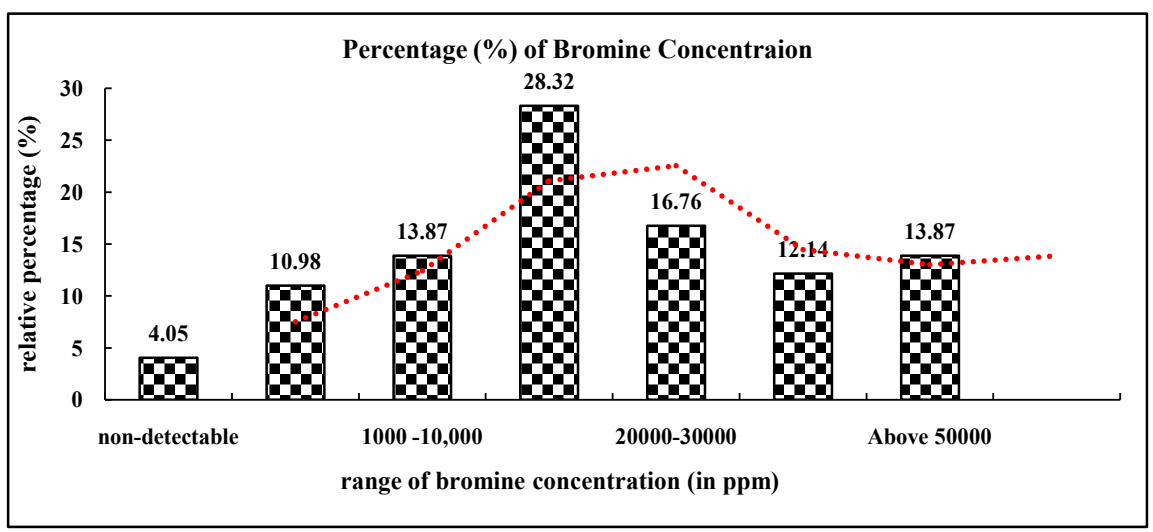

Figure 1. The percentage of bromine in computers determined using Genius 3000 XRF.

manufactured at different times was 425 (1981), 22052 (1995), 0.4006 (1996), 56,032 (2001), and 67,845 (2002). The same case was observed in DELL and the results were 28,314 (obtilex 1994), 10472 (dimension 1996), 26,463 (1997), 32,501 (2002), 15,786 (2003), and 0 (2004). Some possible reasons for the variation of $\mathrm{Br}$ could be due to the manufacturer's use of different levels of BFRs or the use of other types of flame retardants. Moreover, the temperature and time to which the products manufactured, the nature of the stores used, and the difference in the sample parts analysed could be additional reasons.

Based on the preliminary survey, the quantity of obsolete computers and other e-wastes temporarily stored in ordinary stores is growing at an alarming rate. Mostly, those wastes are mixed with other materials or wastes and are sometimes placed in an open area. This could be due to lack of storage facilities and 
Table 2. Samples of obsolete computers screened and their bromine concentration (ppm).

\begin{tabular}{ccc}
\hline Brand & Manufacturing time & Amount of Br (ppm) \\
\hline DELL & $\#$ & $51,542.3516$ \\
DELL dimention & 1996 & $10,472.4833$ \\
IBM & 1981 & 424.8742 \\
IBM & 2002 & $67,844.6843$ \\
Belina & 1990 & $62,043.2443$ \\
Philips & 1984 & $69,569.5217$ \\
Likon & 1999 & $76,987.8613$ \\
AGC & 1996 & $36,220.9069$ \\
Fujitsu & 1993 & $27,869.7014$ \\
Samsung & 1997 & $32,557.6516$ \\
NCC & 2004 & $57,016.1862$ \\
Threei & 1996 & $84,463.9658$ \\
RM & 1998 & $37,685.5699$ \\
Getway & 2004 & $73,410.3382$ \\
Adi & 1997 & $75,410.3382$ \\
\hline
\end{tabular}

NB: \# manufacturing time was not found.

inadequate infrastructure for WEEE management, and very low awareness of the users. In this study, the levels of bromine in samples of computers still functioning were also screened. As shown in Table 3, the quantity of bromine was found mainly above the level (i.e. $1000 \mathrm{ppm}$ or $<0.1 \%$ by weight) of EU Directive (2017/2102) [25] in EEEs implemented in 2006. However, some lately manufactured products showed low levels of Br (ppm); Lenovo 2015 (134 ppm) and Dell 2013 (44 ppm) and these satisfied the RoHS directive. The analysis indicates that there is still possibility of finding computers in the market with high level of BRFs. Therefore, there should be a mechanism to scrutinize and thus monitor the importation of electronic equipments. Moreover, the Ministry in charge should implement national legislation framework related to the assembly and importation of new electrical equipment.

The XRF screening results displayed in Table 4 was obtained from the unassembled computer parts found in Asha-Golgol. The level of $\mathrm{Br}$, from different manufacturers was much higher than the RoHS directive maximum concentration value. The result indicated that, there is a possibility to get computers having high level of $\mathrm{Br}$ even in new casings and thus purchasers should be aware of this matter. Besides, this result clearly indicated that BFRs are still used in some computer parts.

\subsection{Televisions}

The samples of televisions assessed were from private sectors such as repairing shops and vocational training centers. Most of the repairing shops are situated 
Table 3. Samples of Br concentration ( $\mathrm{ppm}$ ) in computers still in use.

\begin{tabular}{ccc}
\hline Functioning computers & Manufacturing time & Amount of Br (ppm) \\
\hline Lenovo & 2015 & 137.9724 \\
HP DX2400 & 2008 & 8361.3373 \\
HCL 2010 & 2010 & 8564.9352 \\
DELL optiplex GX270 & 2003 & $15,726.006$ \\
Acer & 2010 & 9752.2376 \\
DELL India & 2013 & 43.5646 \\
\hline
\end{tabular}

Table 4. Samples of screened unassembled computer parts found in Asha-Golgol.

\begin{tabular}{ccc}
\hline Component type & Manufacturing time & Amount of Br (ppm) \\
\hline power supply & $\#$ & $20,074.0372$ \\
mb. LM915 & $\#$ & $13,028.6725$ \\
mb.LMH61 & $\#$ & $11,789.3379$ \\
mb.foxconn & 2010 & $17,278.4158$ \\
mb.elitegroup & 2007 & $14,619.7124$ \\
mb.hasee & 2007 & $15,130.4659$ \\
mb NCC & $\#$ & $20,914.7472$ \\
HD & $\#$ & $14,951.4704$ \\
\hline
\end{tabular}

NB: “\#” manufacturing time was not found; "mb" motherboard.

along with other business and residential areas. The workshops are congested and thus different TV parts are kept together without proper storage conditions. Besides, the technicians are usually working without adequate personal protective equipment and others do the repairing in their living houses; thus exposing themselves, their families, local residents and the environment to the dangerous pollutants especially via dust ingestion. In this study, 50 TV samples including old and lately imported products were screened. As indicated in Table 5 and Figure 2, a total of around 1.2 kilogram of $\mathrm{Br}$ was measured varying from lowest detectable amount (1.5793 ppm) to the highest $(80,916 \mathrm{ppm})$. Due to the storage problems in the repairing shops, any material which doesn't function is usually discarded away and this increases the WEEE. E-wastes contain multiple toxic substances that are hazardous to human health and the environment; therefore even a small amount of e-waste entering the residual wastes will add up relatively high amount toxic substances.

Generally, from the screened samples, 4 TVs (8\%) were found below the detection limit, and $8(16 \%)$ had $\mathrm{Br}$ concentration below $1000 \mathrm{ppm}$. Majority of the samples, 22 (44\%) were found with $\mathrm{Br}$ level between 10,000 to 30,000 ppm. Moreover, 7 (14\%) TVs had concentration of 30,000 up to 50,000 ppm and 9 (18\%) were found with much higher $\mathrm{Br}$ concentration (>50,000 ppm). Similar to the analysis of computers, the highest level of bromine in TVs was observed in 
Table 5. Range of bromine concentration ( $\mathrm{ppm}$ ) measured from TVs.

\begin{tabular}{ccc}
\hline Range (ppm) & Total & Percent \\
\hline$<$ detection limit & 4 & 8 \\
$>0 \leq 1000$ & 8 & 16 \\
$>1000 \leq 10,000$ & 4 & 8 \\
$>10,000 \leq 20,000$ & 11 & 22 \\
$>20,000 \leq 30,000$ & 7 & 14 \\
$>30,000 \leq 40,000$ & 5 & 10 \\
$>40,000 \leq 50,000$ & 2 & 4 \\
$>50,000 \leq 60,000$ & 2 & 4 \\
$>60,000 \leq 70,000$ & 4 & 8 \\
$>70,000$ & 3 & 6 \\
Total & 50 & 100 \\
\hline
\end{tabular}

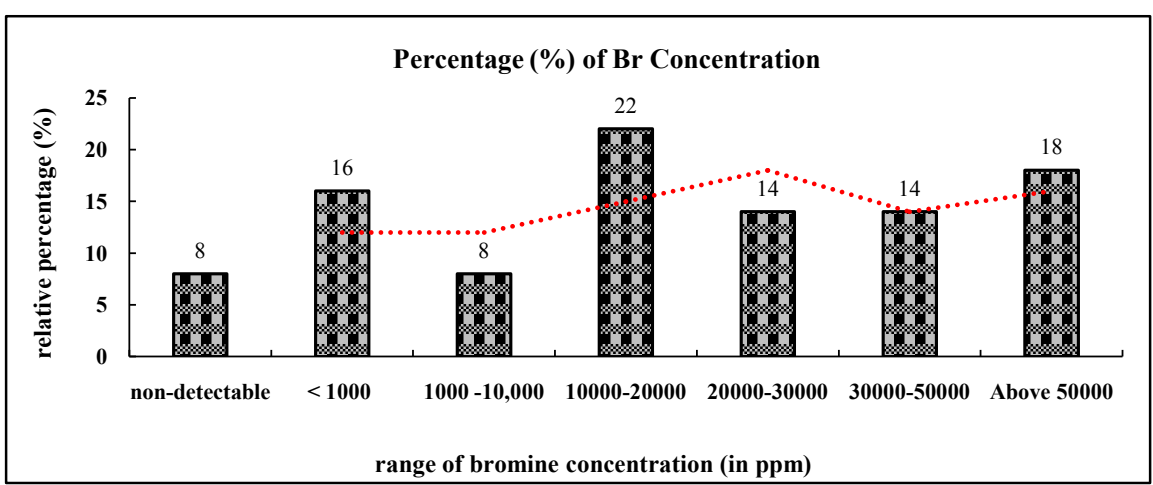

Figure 2. The percentage of bromine in TVs determined using Genius 3000 XRF.

the range of $10,000-20,000 \mathrm{ppm}$. Relatively, the trend shows that there were large percentage of TVS with extreme level $(>50,000 \mathrm{ppm})$ of Bromine and thus large portion of the highly toxic polybrominated flame retardants. According to Korcz, et al. (2014) [26], heating the electrical devices during operation as well as UV irradiation are the main factors to the release of PBDEs from TVs. A $5^{\circ} \mathrm{C}$ rise in temperature has been shown to increase the emission of PBDEs from television casings to the environment from $40 \%$ to $70 \%$. From this it can be suggested that every user is exposed to those chemicals even at low amounts; children and individuals in which their daily life are related to repairing and indoor activities are highly exposed. The results of the XRF screening (Table 6) clearly indicates that BFRs are highly employed in different brands of TVs including the lately manufacture products. However, like the case of computers, the amount of Br didn't show any consistency regarding to either product type or manufacturing time. For example, the amount of $\mathrm{Br}$ (inppm) was found to be 30,143 in Sony wega, 35,582 in Sony tritron (both CRTs), and 68,591 in Sony (LCD). Similar results were obtained in Sharp 2004 (12,809), Zenith 1995 (65,397), Samsung 2011 (35,326), Samsung $2013(19,981)$, and LG $2012(16,683)$. 
Table 6. Samples of televisions screened for bromine.

\begin{tabular}{|c|c|c|}
\hline TV name & Manufacturing time & Amount of $\mathrm{Br}(\mathrm{ppm})$ \\
\hline Sanyo* & \# & 574.0035 \\
\hline Philps* & $\#$ & 824.3209 \\
\hline $\mathrm{RMC}^{*}$ & \# & 1552.5406 \\
\hline Aiwa $^{*}$ & $\#$ & $80,916.4919$ \\
\hline $\mathrm{LG}^{*}$ & $\#$ & $54,690.8849$ \\
\hline Samsung* & $\#$ & $71,729.7516$ \\
\hline Sony Tritron* & $\#$ & $35,582.8421$ \\
\hline SHARP* & 2004 & $12,809.6396$ \\
\hline ZENITH $^{*}$ & 1995 & $65,397.7278$ \\
\hline SONY* $^{*}$ & $\#$ & $64,779.6055$ \\
\hline LED Samsungmalasia & 2013 & $19,981.5015$ \\
\hline LCD Samsung china & 2011 & $35,326.4404$ \\
\hline Plasma Samsung china & 2012 & $24,776.6682$ \\
\hline Plasma HCT & 2009 & 9707.4004 \\
\hline LG Korea & 2012 & $16,683.3133$ \\
\hline Changhong & 2012 & $13,836.8859$ \\
\hline LCD Sony & $\#$ & $68,519.2829$ \\
\hline LG universal & 2015 & 5137.8747 \\
\hline
\end{tabular}

NB: * CRT TVs, \# manufacturing time was not found.

\section{Conclusion}

In Eritrea, the current lack of e-waste management framework and extremely low awareness has resulted into institutions and individuals storing their wastes in offices, homes and/or along with other types of materials. This preliminary XRF data for brominated flame retardants and the survey conducted related to e-waste management clearly indicated that there is high potential of environmental pollution as well as human exposure in the country. Sustainable management of e-waste stream not only safeguards the environment and human health from the hazards posed by the hazardous chemicals available in the e-wastes, but can also serve as an avenue to create employment and investment opportunities. Unless urgent suitable safety measures both for handling and disposing in a sustainable manner are taken, the growth of E-wastes will have significant economic, environmental as well as social impacts. To evaluate the environmental as well as health hazardous of PBDEs and other toxic materials of e-waste, further study using advanced analytical methods is mandatory.

\section{Acknowledgements}

We extend our sincere acknowledgement to the Department of Environment of the Ministry of Land, Water and Environment for their assistance in data analy- 
sis using their instrument (Genius $3000 \mathrm{XRF}$ ).

\section{Conflicts of Interest}

The authors declare that there is no conflict of interest in the overall project and publication of this manuscript.

\section{References}

[1] Lobo, E., Vinod, D.C. and Lasrado, S.A. (2016) Study and Analysis of Disposal of Electronic Waste and Its Effect on the Environment. International Journal Latest Trends in Engineering Technology, Special Issue SACAIM 2016, 273-277.

[2] Shamim, A., Mursheda, K.A. and Rafiq, I. (2015) E-Waste Trading Impact on Public Health and Ecosystem Services in Developing Countries. International Journal of Waste Resources, 5, 1-10. https://doi.org/10.4172/2252-5211.1000188

[3] Sitaramaiah, Y. and Kusuma, K.M. (2014) Impact of Electronic Waste Leading to Environmental Pollution. Journal of Chemical and Pharmaceutical Sciences, Special Issue, 3, 1974-2115.

[4] Sivaramanan, S. (2013) E-Waste Management, Disposal and Its Impact on the Environment. Universal Journal of Environmental Research and Technology, 3, 531-537.

[5] Baldé, C.P., Forti, V., Gray, V., Kuehr, R. and Stegmann, P. (2017) The Global E-Waste Monitor-2017. United Nations University (UNU), International Telecommunication Union (ITU) \& International Solid Waste Association (ISWA), Bonn/Geneva/Vienna.

[6] National Productivity Council (2017) Tool Kit on E-Waste Management Rules. National Productivity Council, New Delhi.

[7] Nartey, K.V. (2016) Environmental and Health Impacts of Informal E-Waste Recycling in Agbogbloshie, Accra, Ghana: Recommendations for Sustainable Management. Dissertation, Rheinischen Friedrich-Wilhelms-Universität Bonn. http://hss.ulb.uni-bonn.de/2016/4325/4325.pdf

[8] Lundgren, K. (2012) The Global Impact of E-Waste: Addressing the Challenge. International Labour Organization, Geneva.

[9] Swedish Environmental Protection Agency, SEPA (2011) Recycling and Disposal of Electronic Waste, Report No 6417. Naturvårdsverket, Bromma, Sweden.

[10] Gkaidatzis, G., Aggelakoglou, K. and Aktsoglou, D. (2009) E-Waste Environmental Problems and Current Management, Democritus University of Thrace, Xanthi GR-67100. Greek-Chinese Forum on the Environment, Athens, 3-4 December 2009.

[11] Robinson, B.H. (2009) E-Waste: An Assessment of Global Production and Environmental Impacts. Science of the Total Environment, 408, 183-191. https://doi.org/10.1016/j.scitotenv.2009.09.044

[12] Agnihotri, V.K. (2011) E-Waste in India. RajyaSabha Secretariat, New Delhi.

[13] Tohka, A. and Zevenhoven, R. (2001) Processing Wastes and Waste-Derived Fuels Containing Brominated Flame Retardants. Helsinki University of Technology Department of Mechanical Engineering, Helsinki.

[14] Masayuki, S., Go, S., Alin, C., Nguyen, M.T., Fuchao, X., Hidenori, M., et al. (2016) Occurrence of Emerging Flame Retardants from E-Waste Recycling Activities in the Northern Part of Vietnam. Emerging Contaminants, 2, 57-118.

[15] Abushawish, J. and Turner, S. (2010) E-Waste and the Environment the Case for 
Electronics Recycling Legislation, Version 1.0. Goodwill Industries International Inc., USA.

[16] Danon-Schaffer, M.N. (2010) Polybrominated Diphenyl Ethers in Landfills from Electronic Waste. PhD Thesis, The University of British Columbia, Vancouver.

[17] Dirtu, A.C. (2009) Analytical Aspects for Determination of Polybrominated Diphenyl Ethers in Environmental Samples. Acta Chemica Iasi, 17, 107-119.

[18] Al-Omran, L.S.Z. (2016) Factors Influencing Human Exposure Assessments of Legacy and "Novel" Brominated Flame Retardants via Indoor Dust Ingestion. PhD Thesis, The University of Birmingham, Birmingham.

[19] Allen, J.G., Gale, S., Zoeller, R.T., Spengler, J.D., Birnbaum, L. and McNeely, E. (2016) PBDE Flame Retardants, Thyroid Disease, and Menopausal Status in U.S. Women. Environmental Health, 15, 60. https://doi.org/10.1186/s12940-016-0141-0

[20] David, S., Iryna, L., Helen, D., Paul, J., Mark, S. and Oliver, K. (2003) Consuming Chemicals Hazardous Chemicals in House Dust as an Indicator of Chemical Exposure in the Home. Green Peace Research Laboratories, Department of Biological Sciences, University of Exeter, Exeter.

[21] vanBergen, S., Davies, H., Grice, J., Mathieu, C. and Stone, A. (2015) Flame Retardants. No. 14-04-047, Washington State Department of Ecology, Olympia, Washington DC.

[22] Makey, C.M., McClean, M.D., Braverman, L.E., Pearce, E.N., Xue-Mei, H., Sjödin, A., Weinberg, J.M. and Webster, T.F. (2016) Polybrominated Diphenyl Ether Exposure and Thyroid Function Tests in North American Adults. Environmental Health Perspectives, 124, 420-425. https://doi.org/10.1289/ehp.1509755

[23] Chao, H.R., Huang, H.L., Hsu, Y.C., Lin, C.W., Lin, D.Y., Gou, Y.Y. and Chen, K.C. (2014) Impact of Brominated POPs on the Neurodevelopment and Thyroid Hormones of Young Children in an Indoor Environment. Aerosol and Air Quality Research, 14, 1320-1332. https://doi.org/10.4209/aaqr.2013.05.0156

[24] U.S. Environmental Protection Agency (2006) Polybrominated Diphenyl Ethers (PBDEs) Project Plan.

[25] EU Directive 2017/2102 of the European Parliament and of the Council of 15 November 2017 Amending Directive 2011/65/EU on the Restriction of the Use of Certain Hazardous Substances in Electrical and Electronic Equipment. http://data.europa.eu/eli/dir/2017/2102/oj

[26] Korcz, W., Struciński, P., Góralczyk, K., Hernik, A., łyczewska, M., Czaja, K., Matuszak, M., Minorczyk, M. and Ludwicki, J.K. (2014) Development and Validation of a Method for Determination of Selected Polybrominated Diphenyl Ether Congeners in Household Dust. National Institute of Public Health/National Institute of Hygiene, 65, 93-100. 